\title{
Evaluation of risk of liver metastasis in colorectal adenocarcinoma based on the combination of risk factors including CD10 expression: Multivariate analysis of clinicopathological and immunohistochemical factors
}

\author{
YUTAKA OHJI $^{1,2}$, TAKASHI YAO ${ }^{1}$, TAKASHI EGUCHI $^{1}$, TOMOMI YAMADA $^{3}$, \\ MINAKO HIRAHASHI ${ }^{1,2}$, MITSUO IIDA ${ }^{2}$ and MASAZUMI TSUNEYOSHI ${ }^{1}$ \\ Departments of ${ }^{1}$ Anatomic Pathology, ${ }^{2}$ Medicine and Clinical Science, Graduate School of Medical \\ Sciences of Kyushu University; ${ }^{3}$ Department of Medical Informatics, Kyushu University \\ Hospital, Maidashi 3-1-1, Higashi-ku, Fukuoka 812-8582, Japan
}

Received March 28, 2006; Accepted June 29, 2006

\begin{abstract}
Evaluation of the relationship between clinicopathological and immunohistochemical risk factors for liver metastasis, including CD10 expression, is meaningful in colorectal carcinoma (CRC). The purpose of the present study was to clarify what kind of risk factors are significant and independent factors for the development of liver metastasis in CRC. Sixty cases of advanced CRC with synchronous liver metastasis and sixty cases of advanced CRC without liver metastasis at least 5 years after resection of the primary CRC were randomly selected. We analysed the clinicopathological factors and the expression of four biological factors, CD44, transforming growth factor alpha (TGF- $\alpha$ ), vascular endothelial growth factor (VEGF) and CD10, by immunohistochemistry. Univariate analysis revealed that the incidence of vascular invasion, the incidence of lymph node metastasis and the expression of CD44, TGF- $\alpha$, VEGF and CD10 were all significantly higher in the cases of CRC with liver metastasis than in cases of non-metastatic CRC. Logistic regression analysis showed that lymph node metastasis, the expression of CD10 and the expression of VEGF were significant factors and independent of the other variables. If all three markers are positive, the probability of liver metastasis becomes $92.7 \%$. In this study, lymph node
\end{abstract}

Correspondence to: Dr Takashi Yao, Department of Anatomic Pathology, Graduate School of Medical Sciences, Kyushu University, 3-1-1 Maidashi, Higashi-ku, Fukuoka, 812-8582, Japan

E-mail: takyao@surgpath.med.kyushu-u.ac.jp

Key words: colorectal carcinoma, liver metastasis, CD10, vascular endothelial growth factor metastasis, CD10 and VEGF were all found to be significant risk factors for the development of liver metastasis in the cases of CRC. These risk factors according to multivariate analysis are candidate markers for predicting the development of liver metastasis.

\section{Introduction}

Colorectal carcinoma (CRC) is one of the major causes of cancer death worldwide $(1,2)$. Liver metastasis is the most critical prognostic factor for CRC, although several studies have revealed the benefits of surgical removal of metastasis from patients with CRC (3-5). Therefore, the early detection of liver metastasis is important for improving patient survival. For the prediction of liver metastasis in CRC, it is important to investigate the risk factors involved in the development of liver metastasis. Histopathologically, the presence of venous invasion $(13,15)$, a deeper level of invasion, less differentiation of the carcinoma and the presence of lymph node metastasis $(3,25)$ have all been reported to be risk factors. Immunohistochemically, the biological factors related to liver metastasis have been identified as TGF- $\alpha(6,7)$, VEGF $(6,8)$ and CD44 $(11,12,36)$.

Through recent advances in mucin histochemistry and immunohistochemistry, it has become clear that gastrointestinal adenocarcinoma can be classified according to phenotypic expression (17-19). Some authors have also reported that phenotypic expression is related to the tumor growth pattern and aggressiveness $(19,20,22)$. In colorectal adenocarcinoma, a correlation between CD10 expression and a high incidence of liver metastasis has been reported (22).

An investigation into the relationship between clinicopathological and immunohistochemical risk factors including CD10 expression is essential. The purpose of the present study was to clarify what kind of risk factors are significant and independent factors for the development of liver metastasis in CRC. 
Table I. Comparison of clinicopathological features between the CRCs with liver metastasis and the control CRCs.

\begin{tabular}{|c|c|c|c|}
\hline & $\begin{array}{l}\text { CRCs with liver metastasis } \\
\qquad(\mathrm{n}=60)\end{array}$ & $\begin{array}{l}\text { Control CRCs } \\
\qquad(\mathrm{n}=60)\end{array}$ & P-value \\
\hline Age (years) & $64.9 \pm 9.3$ & $64.0 \pm 9.5$ & NS \\
\hline Sex (male:female) & $37: 23$ & $36: 24$ & NS \\
\hline Size $(\mathrm{mm})$ & $54.9 \pm 20.3$ & $49.2 \pm 19.2$ & NS \\
\hline Location (right:left) & $16: 44$ & $18: 42$ & NS \\
\hline $\begin{array}{l}\text { Histological type } \\
\text { Well } \\
\text { Mod } \\
\text { Poor+muc }\end{array}$ & $\begin{array}{r}25 \\
32 \\
3\end{array}$ & $\begin{array}{r}37 \\
22 \\
1\end{array}$ & NS \\
\hline $\begin{array}{l}\text { Lymphatic permeation } \\
\text { Positive } \\
\text { Negative }\end{array}$ & $\begin{array}{l}34 \\
26\end{array}$ & $\begin{array}{l}29 \\
31\end{array}$ & NS \\
\hline $\begin{array}{l}\text { Venous invasion } \\
\text { Positive } \\
\text { Negative }\end{array}$ & $\begin{array}{l}41 \\
19\end{array}$ & $\begin{array}{l}29 \\
31\end{array}$ & 0.041 \\
\hline $\begin{array}{l}\text { Lymph node metastasis } \\
\text { Positive } \\
\text { Negative }\end{array}$ & $\begin{array}{l}44 \\
16\end{array}$ & $\begin{array}{l}21 \\
39\end{array}$ & $<0.0001$ \\
\hline
\end{tabular}

NS, not statistically significant; well, well differentiated; mod, moderately differentiated; poor, poorly differentiated; muc, mucinous; CRCs, colorectal carcinomas.

\section{Materials and methods}

Sixty cases of advanced colorectal adenocarcinoma with synchronous liver metastasis were randomly selected for this study from the surgical files of the Department of Anatomic Pathology, Graduate School of Medical Sciences, Kyushu University, Fukuoka, Japan. The cases had been collected from its affiliated hospitals. For the control cases, sixty cases of CRC without liver metastasis at least 5 years after resection of the primary $\mathrm{CRC}$ were randomly selected. In the control cases, patients had been followed-up by a CT scan or an ultrasonography twice or more in a year. All the cases were T3 stage or more. The histological classification was based on the Japanese Classification of Colorectal Carcinoma (16).

Paraffin-embedded blocks from all the cases were available for immunohistochemistry. One representative section of each primary lesion, including the deepest level of tumor penetration, was processed for immunohistochemical staining using antibodies against CD10 (56C6, Novocastra; diluted 1:100), TGF- $\alpha$ (213-4.4, Oncogene Research Products; diluted 1:200), VEGF (A20, Santa Cruz Biotechnology; diluted 1:100) and CD44v6 (VFF-18, Chemicon; diluted 1:500). Sections of $4 \mu \mathrm{m}$ were cut, deparaffinised in xylene, and dehydrated in a descending dilution of ethanol. Endogenous peroxidase activity was blocked by $30 \mathrm{~min}$ of incubation with $0.3 \%$ hydrogen peroxidase in absolute methanol. For antigen retrieval, slides for CD10, TGF- $\alpha$, VEGF and CD44 immunostains were treated by microwave heating in citrate buffer $(10 \mathrm{mmol} / \mathrm{l}, \mathrm{pH} 6.0)$ for $30 \mathrm{~min}$. Background staining was minimized by incubation with $1 \%$ normal goat or rabbit serum for $10 \mathrm{~min}$. Sections were incubated with a primary antibody overnight at $4{ }^{\circ} \mathrm{C}$ followed by testing with a streptavidin-biotin-peroxidase kit (Nichirei, Japan). Diaminobenzidine tetrahydrochloride was used as the chromogen. Finally, sections were counterstained with Mayer's hematoxylin.

The results of staining were categorized as positive when $\geq 10 \%$ of the carcinoma cells were stained and negative when $<10 \%$ of the carcinoma cells were stained. Each slide was observed independently by the two investigators, neither of whom had any knowledge of the clinicopathological features. The comparison between the CRCs with liver metastasis and the control CRCs was performed by univariate and multivariate analysis. For univariate analysis, we performed the t-test (age and size), Fisher's exact test (histological type) and the Chi-square test (other factors). Multivariate analysis was performed using stepwise logistic regression analysis. A probability value $<0.05$ was considered statistically significant. The statistical analysis was carried out using the SAS software package (version 8.2).

\section{Results}

Clinicopathological features of CRCs with liver metastasis and control CRCs. The clinicopathological features of the CRCs with liver metastasis and the control CRCs are summarized in Table I. There was no significant difference in 
A
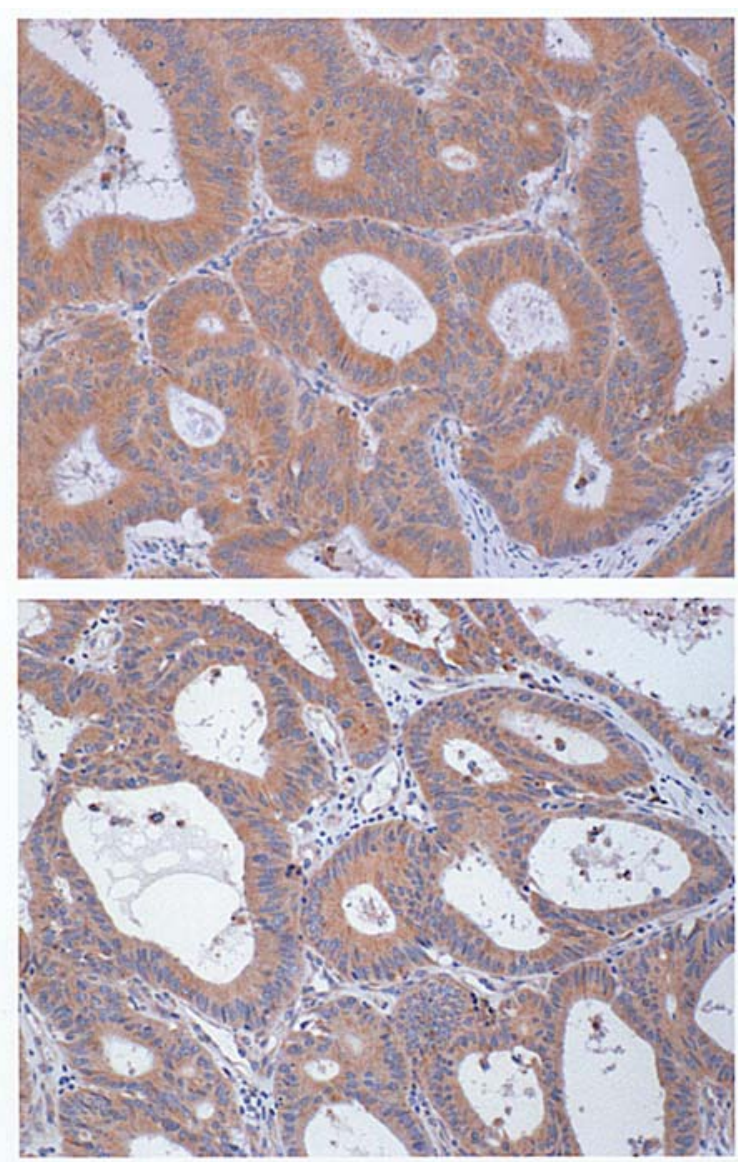
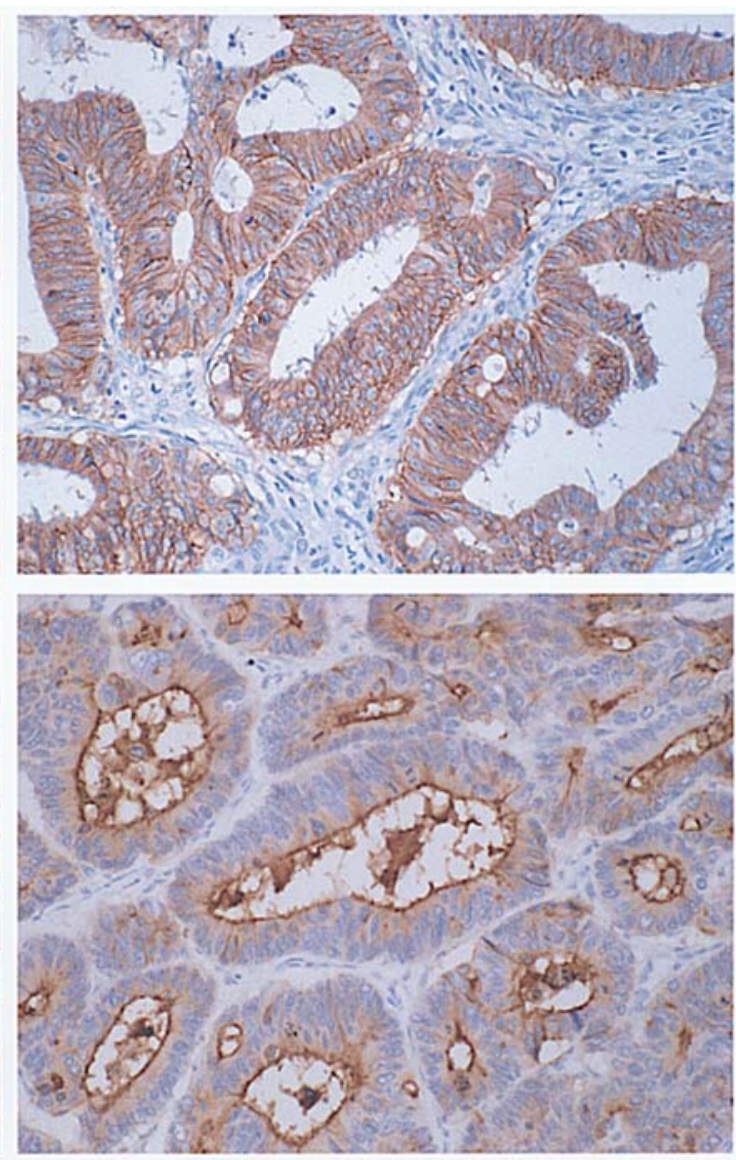

Figure 1. Positive immunohistochemical staining of TGF- $\alpha$, CD44, VEGF and CD10 in colorectal adenocarcinoma. (A) TGF- $\alpha$ is expressed within the cytoplasm of the carcinoma. (B) CD44 is expressed on the cell membrane of the carcinoma. (C) VEGF is expressed within the cytoplasm of the carcinoma. (D) CD10 is expressed along the luminal surface of the glands. Original magnification, $\mathrm{x} 200$.

Table II. Expression of immunohistological factors in the primary tumors of CRCs with liver metastasis and the control CRCs.

\begin{tabular}{lccc}
\hline & $\begin{array}{c}\text { CRCs with } \\
\text { liver metastasis } \\
(\mathrm{n}=60)\end{array}$ & Control CRCs & P-value \\
& & $\mathrm{n}=60)$ & \\
\hline CD10 & 37 & 15 & 0.0001 \\
$\quad$ Positive & 23 & 45 & \\
Negative & & & 0.037 \\
TGF- $\alpha$ & 28 & 16 & \\
$\quad$ Positive & 32 & 44 & \\
Negative & & & 0.016 \\
VEGF & 55 & 44 & \\
Positive & 5 & 16 & \\
Negative & & & 0.042 \\
CD44 & 32 & 20 & \\
Positive & 28 & 40 & \\
Negative & & & \\
\hline
\end{tabular}

age, sex, size or location between these tumors. Histologically, CRCs with liver metastasis tended to be less differentiated than the control CRCs, but this difference was not significant. The incidence of lymphatic permeation did not differ between them, but the incidence of venous invasion in the CRCs with liver metastasis $(41 / 60,68.3 \%)$ was significantly higher than that in the control CRCs $(29 / 60$, 48.3\%). Lymph node metastasis in the CRCs with liver metastasis $(44 / 60,73.3 \%)$ was also significantly higher than that in the control CRCs $(21 / 60,35 \%)$.

Expression of immunohistological factors in primary tumors of cases of CRC with liver metastasis and cases of control CRC. In the positive cases, TGF- $\alpha$ and VEGF ware stained within the cytoplasm (Fig. 1A and C). CD44 demonstrated a membranous staining pattern (Fig. 1B), while CD10 was stained along the luminal surface of the glands (Fig. 1D).

Table II summarizes the expression of immunohistochemical factors in the primary tumors. The incidence of $\mathrm{CD}$ 10, TGF- $\alpha$, VEGF and CD44 expression in the CRCs with liver metastasis was $61.6 \%(37 / 60), 46.6 \%$ (28/60), $91.6 \%$ $(55 / 60)$ and $53.3 \%(32 / 60)$, respectively. In the control CRCs, the incidence of CD 10, TGF- $\alpha$, VEGF and CD44 expression was $25 \%$ (15/60), $26.6 \%$ (16/60), $73.3 \%$ (44/60) and $33.3 \%(20 / 60)$, respectively. Chi-square analysis revealed that the expression of CD 10, TGF- $\alpha$, VEGF and CD44 was significantly greater in the CRCs with liver metastasis $(\mathrm{p}=0.0001, \mathrm{p}=0.037, \mathrm{p}=0.016, \mathrm{p}=0.042$, respectively) than in the CRCs without liver metastasis. 
Table III. Stepwise logistic regression analysis of the clinicopathological and immunohistochemical factors.

\begin{tabular}{lccc}
\hline & $\begin{array}{c}\text { Odds } \\
\text { ratio }\end{array}$ & $\begin{array}{c}95 \% \text { confidence } \\
\text { intervals }\end{array}$ & P-value \\
\hline Lymph node metastasis & 9.22 & $3.39-25.08$ & $<0.0001$ \\
CD10 & 7.76 & $2.87-20.92$ & $<0.0001$ \\
VEGF & 10.41 & $2.55-42.43$ & 0.0011 \\
Age & & & NS \\
Sex & & & NS \\
Size & & & NS \\
Location & & & $\mathrm{NS}$ \\
Histological type & & & $\mathrm{NS}$ \\
Ly & & & $\mathrm{NS}$ \\
V & & $\mathrm{NS}$ \\
TGF- $\alpha$ & & $\mathrm{NS}$ \\
CD44 & & $\mathrm{NS}$ \\
\hline
\end{tabular}

Ly, lymphatic permeation; V, venous invasion; NS, not statistically significant.

Multivariate analysis of clinicopathological and immunohistochemical factors. Table III shows a stepwise logistic regression analysis of the clinicopathological and immunohistochemical factors. The incidence of lymph node metastasis and the expression of CD10 and VEGF were significantly greater in the CRCs with liver metastasis than in the CRCs without, and these risk factors were independent of the other variables. The odds ratio of lymph node metastasis, the expression of CD10 and the expression of VEGF was 9.22, 7.76 and 10.41 , respectively.

The predicted probability of liver metastasis and possible combinations of lymph node metastasis, expression of CD10 and expression of VEGF by logistic model. Table IV presents the possible combinations of independent risk factors and the predicted probability of liver metastasis. In the cases of CD10 with lymph node metastasis or the cases of CD10 with VEGF positivity, the probability is $79.7 \%$ and $80.7 \%$, respectively. With the combination of all three factors being positive, the probability of liver metastasis becomes $92.7 \%$.

\section{Discussion}

Based on clinicopathology, previous reports have revealed that the risk factors of liver metastasis include the presence of venous invasion $(13,15)$, a deeper level of invasion, less differentiation of the carcinoma and the presence of lymph node metastasis $(3,25)$. In the present series, univariate analysis showed that the incidence of venous invasion and lymph node metastasis was significantly higher in the CRCs with liver metastasis than in the control CRCs, however, when multivariate analysis was used, only lymph node metastasis showed such a significance.

In this study, we evaluated the expression of four biological factors, CD44v6, TGF- $\alpha$, VEGF and CD10, that are related to liver metastasis. CD44 is a transmembranous glycoprotein involved in cell-cell and cell-matrix interactions. This molecule is a cell surface receptor for hyaluronic acid, and it is involved in cell adhesion and migration (30). The CD44 gene has been mapped to the short arm of chromosome 11 . Alternative splicing of this gene, occurring between exon 5 and 16, gives rise to the CD44 isoform, including CD44v6 $(12,30)$. In humans, the correlation between CD44v6 expression and a high rate of liver metastasis has been reported in CRCs $(11,12,36)$.

TGF- $\alpha$ is an autocrine growth factor that plays a role in development and proliferation in normal cells and tissues. It also contributes to cancer progression and metastatic behavior (31). In vitro experiments with human colonic cancer cells revealed that the up-regulation of TGF- $\alpha$ expression in these cells is associated with a progression in tumorigenic properties (32). Immunohistochemically, the overexpression of TGF- $\alpha$ in primary CRCs is associated with the frequency of lymph node metastasis and liver metastasis $(6,33)$.

Angiogenesis in colorectal cancer is a key step in tumor growth, invasion and metastasis. Brown et al first reported that malignant epithelial cells strongly expressed VEGF mRNA in contrast to normal epithelium by in situ hybridization, and that the tumor cells were strongly stained for the VEGF antibody by immunohistochemistry (10). VEGF is a specific mitogen for vascular endothelial cells and it plays an

Table IV. The predicted probability of liver metastasis according to the possible combinations of lymph node metastasis, expression of CD10 and VEGF by logistic model.

\begin{tabular}{|c|c|c|c|c|c|c|c|c|}
\hline \multirow[b]{2}{*}{ Variables } & \multicolumn{8}{|c|}{ Possible combination } \\
\hline & 1 & 2 & 3 & 4 & 5 & 6 & 7 & 8 \\
\hline Lymph node metastasis & - & + & - & - & + & + & - & + \\
\hline CD10 & - & - & - & + & - & + & + & + \\
\hline VEGF & - & - & + & - & + & - & + & + \\
\hline No. of patients & 6 & 6 & 27 & 2 & 29 & 7 & 20 & 23 \\
\hline $\begin{array}{l}\text { Predicted probability } \\
\text { of liver metastasis (\%) }\end{array}$ & 14.3 & 33.6 & 35.0 & 56.4 & 62.1 & 79.7 & 80.7 & 92.7 \\
\hline
\end{tabular}


important role in tumor angiogenesis (14). The expression of VEGF has been found to be correlated with liver metastasis and prognosis $(6,8,9)$.

CD10 was originally used as a marker for the common acute lymphoblastic leukemia antigen (CALLA), but it was found to react with the brush border of the small intestine, as well as with the germinal centers of lymphoid follicles and with the microvilli of the kidney $(21,23)$. It has become clear that gastrointestinal adenocarcinoma can be classified according to phenotypic expression (17-19) and some authors have also reported that phenotypic expression is related to the tumor growth pattern and aggressiveness $(19,20,22)$. CD10 is used as a marker for the brush border, and the expression of CD10 in CRCs suggests a tendency for small intestinal enterocytes to undergo differentiation. In colorectal adenocarcinoma, a correlation between CD10 expression in primary CRC and a high incidence of liver metastasis has been reported (22). An ultrastructural study revealed that microvilli are generated on the luminal surface of metastatic liver adenocarcinomas in CRCs (27). When comparing CD10 expression between the primary and metastatic tumors, it was noted that the CD10 expression in metastatic cancers tended to be similar to that seen in the matched primary CRCs (22).

CD10 is a member of a family of membrane-associated peptidases and it is also known to be a neutral endopeptidase. This enzyme hydrolyzes a variety of peptides by cleaving peptides on the NH2 terminal side of hydrophobic amino acids. A number of physiologically active peptides including neurotensin, bombesin-like peptides, angiotensin, formyl Met-Leu-Phe (fMLP), endothelin, substance P and bradykinin are hydrolyzed by CD10 which limits their activity $(28,29)$. Previously published reports have indicated that some of these peptides, such as bombesin-like peptides and neurotensin, stimulate the proliferation and progression of CRC $(34,35)$. In carcinomas of the lung and the ovary, CD10 inhibits the proliferation of carcinoma by hydrolysis of these peptides $(24,26)$. It is uncertain whether or not CD10 participates in the development of liver metastasis. Many enzymes such as alkaline phosphatase and CD10 are expressed at the brush border of the small intestine, and accordingly it may be that CD10 only exists at the brush border and does not affect the development of liver metastasis. CRCs which have a tendency to differentiate to small intestinal enterocytes, are related to liver metastasis, however, the mechanism behind the metastasis is not yet known.

Lymph node metastasis, the expression of CD10 and the expression of VEGF were significantly greater in the cases of $\mathrm{CRC}$ with liver metastasis than in the cases of CRC without, and these risk factors were independent of the other variables according to stepwise logistic regression analysis. In positive combinations of CD10 plus lymph node metastasis or CD10 plus VEGF, the predicted probability of liver metastasis according to the logistic regression model is $79.7 \%$ and $80.7 \%$, respectively. In the cases where all three factors are positive, the probability becomes $92.7 \%$. Although the mechanism of liver metastasis in the cases of CD10-positive CRC remains unknown, CD10 is a significant marker for liver metastasis in CRC.

In this study, lymph node metastasis, CD10 and VEGF were all significant risk factors for liver metastasis in CRC and these risk factors were independent of the other variables. These risk factors are candidate markers for the prediction of the development of liver metastasis after resection of a primary CRC.

\section{Acknowledgements}

The English used in this manuscript was revised by Miss K. Miller (Royal English Language centre, Fukuoka, Japan).

\section{References}

1. The Editorial Board of the Cancer Statistics in Japan: Cancer Statistics in Japan 2003. Foundation for Promotion of Cancer Research, Tokyo, 2003.

2. Greenlee RT, Murray T, Bolden S and Wingo PA: Cancer statistics 2000. CA Cancer J Clin 50: 7-33, 2000.

3. Shiiki S, Fuchimoto S, Iwagaki H, et al: Clinicopathological study on colorectal cancer with synchronous liver metastasis. J Jpn Soc Coloproctol 44: 1107-1112, 1991.

4. Kortz WJ, Meyers WC, Hanks JB, Schirmer BD and Jones RS: Hepatic resection for metastatic cancer. Ann Surg 199: 182-186, 1984.

5. Coppa GF, Eng K, Ranson JH, Gouge TH and Localio SA: Hepatic resection for metastatic colon and rectal cancer: an evaluation of preoperative and postoperative factors. Ann Surg 202: 203-208, 1985

6. Barozzi C, Ravaioli M, D'Errico A, Grazi GL, Poggioli G, Cavrini G, Mazziotti A and Grigioni WF: Relevance of biologic markers in colorectal carcinoma: a comparative study of a broad panel. Cancer 94: 647-657, 2002.

7. De Jong KP, Stellema R, Karrenbeld A, Koudstaal J, Gouw AS, Sluiter WJ, Peeters PM, Slooff MJ and De Vries EG: Clinical relevance of transforming growth factor alpha, epidermal growth factor receptor, p53, and Ki67 in colorectal liver metastases and corresponding primary tumors. Hepatology 28: 971-979, 1998.

8. Kaio E, Tanaka S, Kitadai Y, Sumii M, et al: Clinical significance of angiogenic factor expression at the deepest invasive site of advanced colorectal carcinoma. Oncology 64: 61-73, 2003.

9. Ishigami SI, Arii S, Furutani M, Niwano M, Harada T, Mizumoto M, Mori A, Onodera $\mathrm{H}$ and Imamura M: Predictive value of vascular endothelial growth factor (VEGF) in metastasis and prognosis of human colorectal cancer. Br J Cancer 78: 1379-1384, 1998.

10. Brown LF, Berse B, Jackman RW, Tognazzi K, Manseau EJ, Senger DR and Dvorak HF: Expression of vascular permeability factor (vascular endothelial growth factor) and its receptors in adenocarcinomas of the gastrointestinal tract. Cancer Res 53: 4727-4735, 1993

11. Nanashima A, Yamaguchi H, Sawai T, Yasutake T, Tsuji T, Jibiki M, Yamaguchi E, Nakagoe T and Ayabe H: Expression of adhesion molecules in hepatic metastases of colorectal carcinoma: relationship to primary tumours and prognosis after hepatic resection. J Gastroenterol Hepatol 14: 1004-1009, 1999.

12. Wielenga VJ, Heider KH, Offerhaus GJ, Adolf GR, van den Berg FM, Ponta H, Herrlich P and Pals ST: Expression of CD44 variant proteins in human colorectal cancer is related to tumor progression. Cancer Res 53: 4754-4756, 1993.

13. Talbot IC, Ritchie S, Leighton MH, Hughes AO, Bussey HJ and Morson BC: The clinical significance of invasion of veins by rectal cancer. Br J Surg 67: 439-442, 1980.

14. Leung DW, Cachianes G, Kuang WJ, Goeddel DV and Ferrara N: Vascular endothelial growth factor is a secreted angiogenic mitogen. Science 246: 1306-1309, 1989.

15. Yamazoe Y, Maetani S, Onodera H, Nishikawa T and Tobe T: Histopathological prediction of liver metastasis after curative resection of colorectal cancer. Surg Oncol 1: 237-244, 1992.

16. Japanese Research Society for Cancer of the Colon and Rectum: Japanese classification of Colorectal Carcinoma, 1st English edition. Kanehara, Tokyo, 1997.

17. Tatematsu M, Ichinose M, Miki K, Hasegawa R, Kato T and Ito $\mathrm{N}$ : Gastric and intestinal phenotypic expression of human stomach cancers as revealed by pepsinogen immunohistochemistry and mucin histochemistry. Acta Pathol Jpn 40: 494-504, 1990.

18. Yao T, Kabashima A,Kouzuki T, Oya M and Tsuneyoshi M: The phenotypes of the gastric carcinoma-evaluation by a new immunohistochemical method. Stomach and Intestine 34: 477$485,1999$. 
19. Yao T, Tsutsumi S, Akaiwa Y, Takata M, Nishiyama K, Kabashima A and Tsuneyoshi M: Phenotypic expression of colorectal adenocarcinomas with reference to tumor development and biological behavior. Jpn J Cancer Res 92: 755-761, 2001

20. Egashira Y: Mucin histochemical study of differentiated adenocarcinoma of stomach. Nippon Shokakibyo Gakkai Zasshi 91: 839-848, 1994.

21. Metzgar RS, Borowitz MJ, Jones NH and Dowell BL: Distribution of common acute lymphoblastic leukemia antigen in nonhematopoietic tissues. J Exp Med 154: 1249-1254, 1981.

22. Yao T, Takata M, Tustsumi S, Nishiyama K, Taguchi K, Nagai E and Tsuneyoshi M: Phenotypic expression of gastrointestinal differentiation markers in colorectal adenocarcinomas with liver metastasis. Pathology 34: 556-560, 2002.

23. Trejdosiewicz LK, Malizia G, Oakes J, Losowsky MS and Janossy G: Expression of the common acute lymphoblastic leukaemia antigen (CALLA gp100) in the brush border of normal jejunum and jejunum of patients with coeliac disease. $\mathrm{J}$ Clin Pathol 38: 1002-1006, 1985.

24. Bunn PA Jr, Helfrich BA, Brenner DG, Chan DC, Dykes DJ, Cohen AJ and Miller YE: Effects of recombinant neutral endopeptidase (EC 3.4.24.11) on the growth of lung cancer cell lines in vitro and in vivo. Clin Cancer Res 4: 2849-2858, 1998.

25. Adachi Y, Inomata M, Kakisako K, Sato K, Shiraishi N and Kitano S: Histopathologic characteristics of colorectal cancer with liver metastasis. Dis Colon Rectum 42: 1053-1056, 1999.

26. Kajiyama H, Shibata K, Terauchi M, Morita T, Ino K, Mizutani S and Kikkawa F: Neutral endopeptidase 24.11/CD10 suppresses progressive potential in ovarian carcinoma in vitro and in vivo. Clin Cancer Res 11: 1798-1808, 2005.

27. Shimizu S, Yamada N, Sawada T, Ikeda K, Nakatani K, Seki S, Kaneda K and Hirakawa K: Ultrastructure of early phase hepatic metastasis of human colon carcinoma cells with special reference to desmosomal junctions with hepatocytes. Pathol Int 50: 953-939, 2000.
28. Zola H: CD10 Workshop Panel report. In: Leucocyte Typing V: White Cell Differentiation Antigens. Schlossman SF, Boumsell L, Gilks W, et al (eds). Oxford University Press, Oxford, pp505-507, 1995.

29. Shipp MA and Look AT: Hematopoietic differentiation antigens that are membrane-associated enzymes: cutting is the key! Blood 82: 1052-1070, 1993.

30. Marhaba R and Zoller M: CD44 in cancer progression: adhesion, migration and growth regulation. J Mol Histol 35 211-231, 2004.

31. Khazaie K, Schirrmacher V and Lichtner RB: EGF receptor in neoplasia and metastasis. Cancer Metastasis Rev 12: 255-274, 1993.

32. Ziober BL, Willson JK, Hymphrey LE, Childress-Fields K and Brattain MG: Autocrine transforming growth factor-alpha is associated with progression of transformed properties in human colon cancer cells. J Biol Chem 268: 691-698, 1993.

33. Saeki T, Salomon DS, Johnson GR, Gullick WJ, Mandai K, Yamagami K, Moriwaki S, Tanada M, Takashima S and Tahara E: Association of epidermal growth factor-related peptides and type I receptor tyrosine kinase receptors with prognosis of human colorectal carcinomas. Jpn J Clin Oncol 25: 240-249, 1995.

34. Tasuta M, Iishi H, Baba M and Taniguchi H: Enhancement by neurotensin of experimental carcinogenesis induced in rat colon by azoxymethane. Br J Cancer 62: 368-371, 1990.

35. Iishi $H$, Tatsuta $M$, Baba $M$, Yamamoto $R$ and Taniguchi $H$ : Enhancement by bombesin of colon carcinogenesis and metastasis induced by azoxymethane in Wistar rats. Int J Cancer 50: 834-839, 1992.

36. Nihei Z, Ichikawa W, Kojima K, Togo S, Miyanaga T, Hirayama R and Mishima Y: The positive relationship between the expression of CD44 variant 6 and prognosis in colorectal cancer. Surg Today 26: 760-761, 1996. 